\title{
Spinal ependymomas. Part 1: Intramedullary ependymomas
}

\author{
Jörg Klekamp, MD \\ Department of Neurosurgery, Christliches Krankenhaus, Quakenbrück, Germany
}

OBJECT Ependymomas represent the most common intramedullary tumor in adults. Despite their usually well-defined dissection plane, surgical morbidity has been documented to be considerably higher compared with other intramedullary entities. This study presents an analysis of risk factors for surgical morbidity and data on long-term results for intramedullary ependymomas.

METHODS Among 1447 patients with tumors of the spinal canal treated between 1980 and 2014, 309 patients presented with intramedullary tumors. One hundred patients with intramedullary ependymomas underwent 102 operations. Mean age was $44 \pm 15$ years (range 8-74 years). Patients were followed by outpatient visits and questionnaires, with a mean follow-up of $77 \pm 91$ months. Short-term results were determined for individual symptoms and the McCormick Scale, whereas tumor recurrence rates were calculated with Kaplan-Meier statistics.

RESULTS Compared with cervical ependymomas, those of the thoracic spine were associated with more severe motor deficits and gait problems at presentation. A total of $86.3 \%$ of patients with intramedullary ependymomas underwent gross-total resection (GTR). A low preoperative McCormick grade and first surgery were the strongest predictors for a GTR. Postoperatively, $67.6 \%$ of patients demonstrated a worse neurological state at discharge from the hospital. This deterioration was transient for $40.1 \%$ of the patients and permanent for $27.5 \%$. In the long term, the McCormick grade remained unchanged from the preoperative grade in $74.5 \%$ of patients, while it was improved in $5.9 \%$ of patients and increased after surgery in $19.6 \%$ of patients. According to a multivariate analysis, the risk of permanent morbidity increased with a thoracic level of the ependymoma, advanced age, a long clinical history, presence of a tumor hemorrhage, and surgery on a recurrent tumor. In the long term, tumor recurrence rates correlated significantly with the amount of resection ( $4.2 \%$ and $18.5 \%$ in 20 years after GTR and partial resections, respectively). Postoperative neuropathic pain syndromes affected $37.0 \%$ of patients, whereas $4 \%$ demonstrated a postoperative myelopathy related to cord tethering at the level of surgery.

CONCLUSIONS Intramedullary ependymomas are tumors best treated surgically. A complete resection indicates cure for the overwhelming majority of these patients. Surgery should be performed early by neurosurgeons who deal with these lesions on a regular basis to achieve high GTR rates. Permanent surgical morbidity varies most according to tumor location and patient age.

http://thejns.org/doi/abs/10.3171/2015.5.FOCUS15161

KEY WORDS intramedullary tumors; syringomyelia; neuropathic pain

I NTRAMEDULLARY spinal cord tumors are rare and challenging pathologies. It is now widely accepted that surgery should be recommended early, before severe neurological deficits have appeared..$^{2,3,5,6,16,32}$ Whereas publications on these tumors in the past decades tended to concentrate on resection results and how to preserve neurological functions, little data exist on surgical mor- bidity or factors that may influence morbidity. Most surgeons would consider ependymomas, which are usually well demarcated from spinal cord tissue, to be associated with less permanent surgical morbidity than those which are more difficult to dissect. However, ependymomas were associated with the highest surgical morbidity rate compared with all other intramedullary tumors in a recent

ABBREVIATIONS GTR = gross-total resection; NF2 = neurofibromatosis Type 2.

SUBMITTED March 30, 2015. ACCEPTED May 19, 2015.

INCLUDE WHEN CITING DOI: 10.3171/2015.5.FOCUS15161.

DISCLOSURE The author reports no conflict of interest concerning the materials or methods used in this study or the findings specified in this paper. 
analysis. ${ }^{11}$ This paper presents a detailed analysis of patients with intramedullary ependymomas treated between 1982 and 2014 to identify factors responsible for their surgical morbidity and possible ways to improve surgical outcomes.

\section{Methods}

A total of 1447 patients presented at the Nordstadt Hospital in Hannover, Germany, between 1980 and 2003 or the Christliche Krankenhaus in Quakenbrück, Germany, from 2004 to 2014 with tumors of the spinal canal and their cases were entered into the spinal cord database. All patients agreed in writing upon admission that their medical data may be used for scientific purposes in anonymous form. Data prior to 1991 were collected retrospectively. Since 1991, all patients have been continuously entered in the database. Apart from general patient data and specific features of each spinal cord pathology, the neurological examinations before surgery, before discharge from the hospital, 3 months postoperatively, and yearly thereafter by outpatient visits and questionnaires were analyzed for individual symptoms according to a scoring system ${ }^{13,15}$ (Table 1) and the McCormick Scale..$^{23}$ Among 1447 patients with spinal tumors, 309 patients presented with intramedullary tumors. Of these, 100 patients with ependymomas underwent a total of 102 operations since 1982. Unless a patient appeared unfit to undergo an operation, surgery was recommended to all symptomatic patients with a de novo tumor. In patients with recurrent tumors, surgery was restricted to patients with evidence of tumor growth or progressive neurological symptoms.

Before the introduction of MRI, the diagnosis was based on CT with contrast or myelography in 3 patients, while the remainder presented with MRI.

All patients were operated on with intraoperative neurophysiological monitoring of somatosensory-evoked potentials. Monitoring of motor-evoked potentials was added routinely in 2011. Patients with cervical tumors were operated on while in the semisitting position and all patients with other tumors were in the prone position. Anesthetists were asked to maintain mean arterial blood pressure at 85 $\mathrm{mm} \mathrm{Hg}$ throughout the intradural dissection. The expo- sure involved laminotomies with reinsertion of the lamina for children, while laminectomies were employed for adults up to the mid 1990s, when lamina were reinserted with increasing frequency in adults as well. Since 1995, all lamina are reimplanted. The microsurgical technique employed was based on the work of Malis ${ }^{20}$ and Stein ${ }^{29}$ and has been published in detail previously ${ }^{11,14}$ (Fig. 1). It was general practice to determine the exact extension of the tumor with ultrasonography before myelotomy. With the exception of exophytic growing ependymomas (Fig. 2), all were removed via a midline approach (Fig. 1). As of 1994, the cord was closed with 7-0 pial sutures after tumor removal.

The following categories were distinguished according to the amount of resection: a gross-total resection (GTR) was defined as no tumor remnant detectable at the end of surgery as well as in the postoperative MRI. A subtotal resection was defined as a complete resection of the tumor mass with a small remnant detectable on the postoperative MRI. A partial resection was defined as an incomplete resection of the tumor mass, while operations with less than $50 \%$ reduction of the tumor mass were classified as biopsies.

The 102 operations were divided among 15 neurosurgeons. Three groups of surgeons were distinguished according to the number of operations performed on all intramedullary tumors: Group A, fewer than 20 operations (11 surgeons, 16 operations); Group B, 20-30 operations (2 surgeons, 15 operations); Group C, more than 70 operations ( 2 surgeons, 71 operations). The overall study period was divided into 3 periods: Period A, 1982-1990 (n = 24); Period B, 1991-2000 $(n=42)$; Period C, 2001-2014 $(\mathrm{n}=36)$.

For statistical tests of significance, Student t-tests and chi-square tests were employed. Means are given with the standard deviation. Results of multiple regression analyses are provided with $\beta$-values to indicate the impact of individual factors, the correlation coefficients of the corresponding regression equations, and their $p$ values. Longterm follow-up was analyzed with Kaplan-Meier statistics ${ }^{9}$ to determine the percentages of patients with tumor recurrences. Differences were considered statistically significant, if a $p$ value $\leq 0.05$ was reached. For all statistical anal-

TABLE 1. Neurological scoring system

\begin{tabular}{|c|c|c|c|c|c|}
\hline Score & Pain & $\begin{array}{l}\text { Sensory Disturbance } \\
\text { Dysesthesias }\end{array}$ & Motor Weakness & Gait Ataxia & Sphincter Function \\
\hline 5 & None & Normal & Full power & Normal & Normal \\
\hline 4 & Slight, no Rx & Present, not significant & $\begin{array}{l}\text { Movement against resis- } \\
\text { tance }\end{array}$ & Unsteady, no aid & $\begin{array}{l}\text { Slight disturbance, } \\
\text { no catheter }\end{array}$ \\
\hline 3 & Good control w/ Rx & $\begin{array}{l}\text { Significant, function not } \\
\text { restricted }\end{array}$ & Movement against gravity & Mobile w/ aid & $\begin{array}{l}\text { Residual, no } \\
\text { catheter }\end{array}$ \\
\hline 2 & $\begin{array}{l}\text { Insufficient control } \\
\quad w / R x\end{array}$ & Some restriction of function & Movement w/o gravity & Few steps w/ aid & Rarely incontinent \\
\hline 1 & Severe despite Rx & Severe restriction of function & Contraction w/o movement & Standing w/ aid & Often, catheter \\
\hline 0 & Incapacitating & Incapacitated function & Plegia & Plegia & Permanent catheter \\
\hline
\end{tabular}

$\mathrm{Rx}=$ medication

Reprinted with modifications from Klekamp J and Samii M: Preface, in Surgery of Spinal Tumors. Berlin: Springer, 2007, p XI-XIII. @SpringerVerlag Berlin Heidelberg 2007. With kind permission of Springer Science+Business Media. 

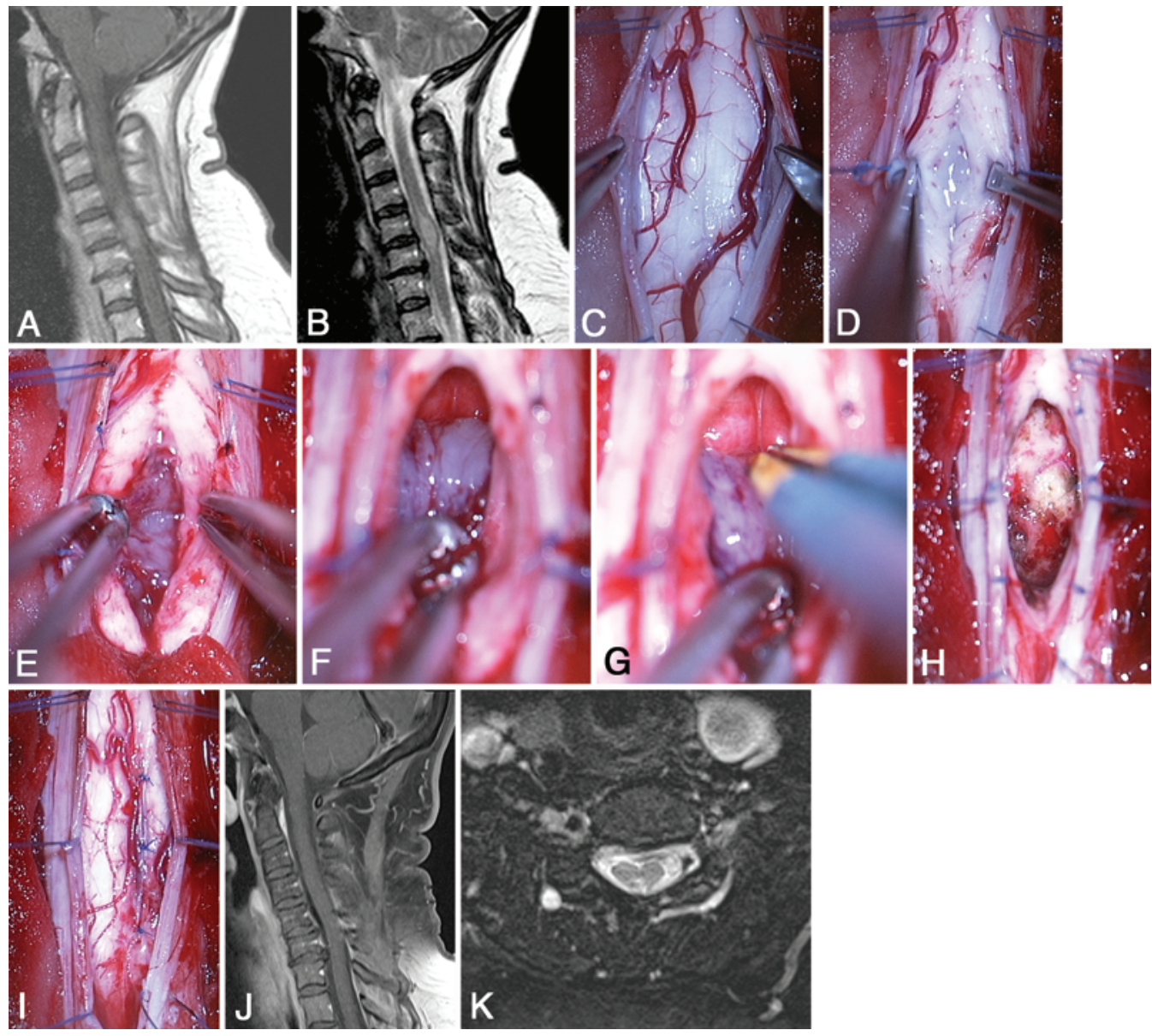

FIG. 1. Case of a 56-year-old woman with an ependymoma at the C5-6 level, with a 2-year history of local pain followed by a slight gait ataxia. A: Sagittal T1-weighted MR image with contrast displays an ill-defined lesion with diffuse boundaries. B: Sagittal T2-weighted MR image demonstrates a clearly demarcated tumor. C-I: Photographs showing intraoperative views throughout tumor resection. In the semisitting position, dura and arachnoid opening displays the midline of the spinal cord marked by a small sulcus (C). After opening of the pia mater, the posterior tracts are spread apart displaying the small vessels in their course along the posterior midline septum of the spinal cord on either side (D). This vascular display marks the anatomical midline of the cord. Once the tumor is reached, the pia is sutured to the dura (E). With continuous debulking a good cleavage plane can be dissected on the right side. The upper pole of the tumor has been dissected free, displaying the ventral part of the tumor bed (F). Small tumor-feeding arteries from the anterior spinal cord artery are isolated, coagulated, and cut (G). In this fashion, the tumor has been completely removed $(\mathrm{H})$. Hemostasis is achieved by repeated irrigation avoiding bipolar coagulation. The cord is closed with 7-0 pia sutures (I). Two years after surgery, the patient's neurological state is unchanged. She developed a pain syndrome, which is well controlled with medication. J and $\mathrm{K}$ : Sagittal T1-weighted MR image $(\mathrm{J})$ with contrast showing no tumor remnant or recurrence, and axial T2-weighted MR image (K) showing only minor adhesions between spinal cord and dura in the midline.

yses the software package "PC-Statistik" version 5.0 was employed (Hoffmann-Software). Surgical morbidity was defined as a permanent aggravation or a new, permanent deficit of motor function, gait, or sphincter function within 30 days after the operation. Sensory functions, dysesthesias, and pain were analyzed separately. A postoperative neuropathic pain syndrome was defined as postoperative neuropathic pain requiring medication. A postoperative myelopathy was defined as a neurological deterioration in the absence of tumor growth or recurrence.

\section{Results}

\section{Preoperative Data}

One hundred patients with intramedullary ependymo- mas underwent 102 operations. The mean age at clinical presentation was $44 \pm 15$ years (range 8-74 years), with an average clinical history of $35 \pm 49$ months. All but 3 patients were adults in this series. Eight patients were affected by neurofibromatosis Type 2 (NF2). Forty-seven ependymomas affected the cervical cord, 52 the thoracic cord, and 3 the conus. Fifty-eight percent of patients demonstrated a syrinx.

Table 2 lists the percentages for individual neurological symptoms to provide an overview of the clinical spectrum. There was a trend toward more severe neurological deficits for thoracic tumors compared with cervical tumors. Overall, $11.2 \%$ of patients were unable to walk, and $4.0 \%$ were incontinent at presentation. During the overall study period, preoperative McCormick grades increased 

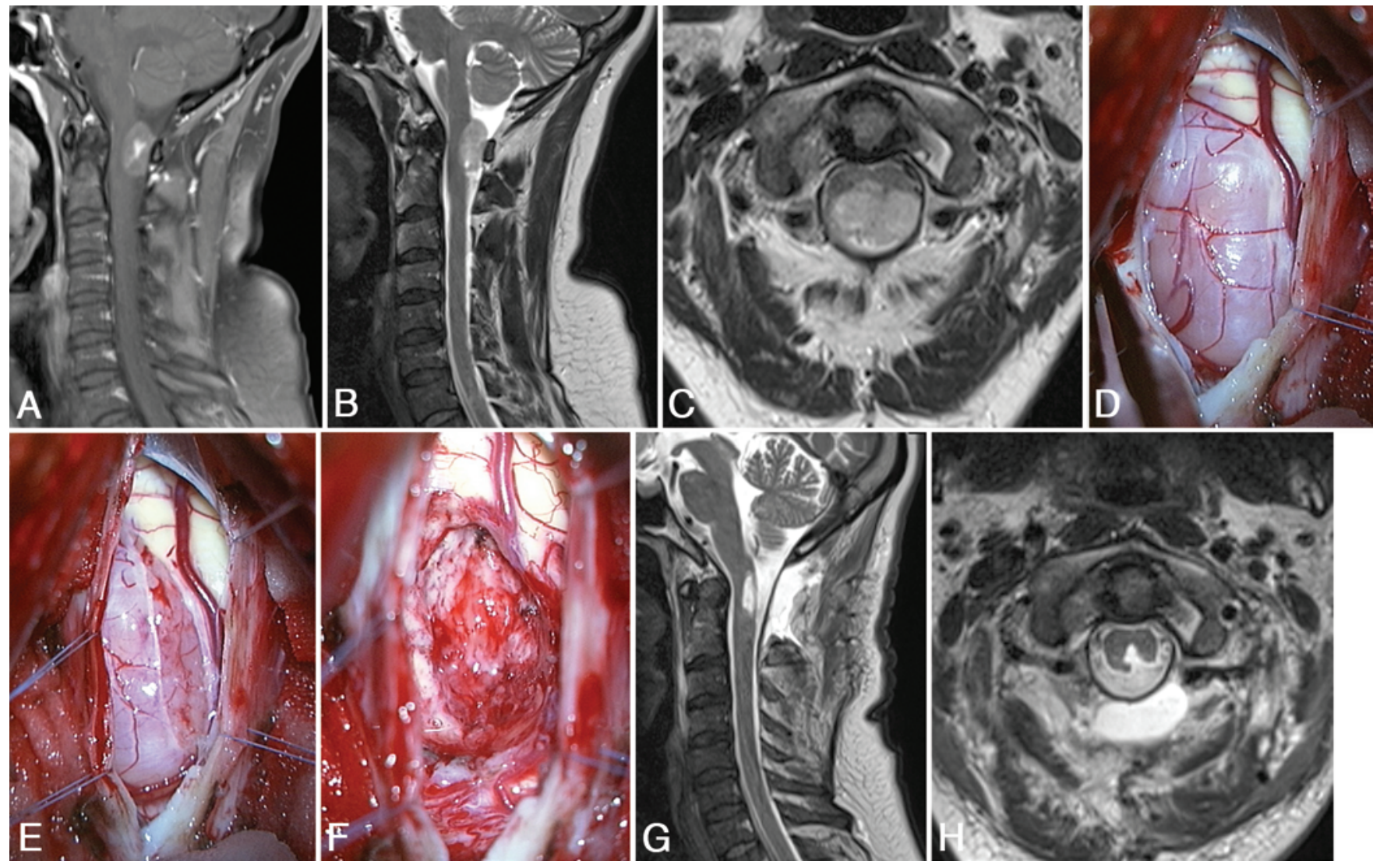

FIG. 2. Case of a 47-year-old woman with an exophytic ependymoma at the C1-2 level, with a 3-month history of a slight tetraparesis. A-C: MR images showing the tumor with varying degrees of enhancement with a clear demarcation. Sagittal T1-weighted MR image (A) and sagittal (B) and axial (C) T2-weighted MR images showing a small cyst in the lower part of the tumor and the exophytic growth of this lesion on the left side. D-F: Photographs showing intraoperative views of the patient in the semisitting position and the tumor can be seen protruding out of the cord on the left side (D). The pia has been incised along the tumor border on the right side (E). With debulking of the tumor a cleavage plane could be followed, as described in Fig. 1, without requiring an additional myelotomy. The tumor has been completely resected (F). G and H: Postoperative sagittal (G) and axial (H) T2-weighted MR images showing the complete resection. The patient's neurological condition remained unchanged without developing a neuropathic pain syndrome.

significantly. Since 1991, $79 \%$ of patients presented in grade I compared with $48 \%$ prior to 1990 . Cervical ependymomas were associated with a significantly lower McCormick grade compared with thoracic tumors (Table 3), even though there was no significant difference in patient preoperative histories.

\section{Management}

GTR was attempted in every patient. Overall, 88 operations $(86.3 \%)$ resulted in GTR, while 7 tumors were removed subtotally, 5 partially, and 2 underwent a biopsy. Thirteen operations involved recurrent tumors. The GTR rate increased continuously from Period A (72\%) and Period B (84\%) to Period C (100\%) (chi-square test: $\mathrm{p}=$ 0.03). The rates varied also according to surgical experience: surgeons in Group A completely removed $71.4 \%$, while those of Group B resected $80 \%$ and those of Group $\mathrm{C}$ removed $90.1 \%$ (chi-square test: $\mathrm{p}=0.03$ ). Comparing tumors with and without syringomyelia revealed no significant difference in GTR rates $(84 \%$ and $89 \%$ with and without syringomyelia, respectively). All tumors but 1 anaplastic ependymoma were classified as WHO Grade II.

In a multivariate analysis, independent factors predicting a GTR were determined (Table 4). The most important

TABLE 2. Symptoms at presentation*

\begin{tabular}{lcccccc}
\hline \multicolumn{1}{c}{ Localization } & Hypesthesia & Dysesthesia & Pain & Motor Weakness & Gait Ataxia & Sphincter Disturbance \\
\hline Cervical $(n=47)$ & 82 & 63 & 47 & 58 & 56 & 23 \\
\hline Thoracic + conus $(n=55)$ & 83 & 56 & 62 & 71 & 83 & 38 \\
\hline All $(n=102)$ & 82 & 58 & 54 & 66 & 73 & 30 \\
\hline
\end{tabular}

* Values are percentages of patients. 
TABLE 3. Preoperative McCormick grades $\uparrow$

\begin{tabular}{ccccccccc}
\hline & \multicolumn{3}{c}{ Overall Period } & & \multicolumn{4}{c}{ Location $\ddagger$} \\
\cline { 2 - 4 } \cline { 7 - 8 } Grade & A & B & C & & Cervical & Thoracic + Conus & All \\
\hline I & $48^{* *}$ & 78 & 80 & & $85^{*}$ & 63 & 72.8 \\
\hline II & $28^{* *}$ & 18 & 14 & & $13^{*}$ & 22 & 18.2 \\
\hline III & $24^{* *}$ & 2 & 4 & & $-^{*}$ & 14 & 7.4 \\
\hline IV & - $^{*}$ & 2 & 2 & & $2^{*}$ & 2 & 1.7 \\
\hline
\end{tabular}

- $=$ no tumor of the given grade was encountered.

$\dagger$ Values are percentage of patients.

* $p=0.02$, chi-square tests.

** $p<0.0001$, chi-square tests.

‡ Shading indicates groups compared for statistical analysis.

factors were a low preoperative McCormick grade and first surgery on the tumor. Other less important predictors were absence of arachnoid scarring between spinal cord and dura, a short clinical history, and an experienced surgeon.

\section{Short-Term Outcome}

Complications were encountered in 17 instances (16.7\%) (Table 5). This rate was irrespective of groups of surgeons or study period subgroups.

A transient, postoperative neurological deterioration was observed for $40.1 \%$ of patients. This rate did not correlate with surgical experience $(43.8 \%$ for surgeons in Group A, $33.3 \%$ for Group B, and $43.7 \%$ for Group C; differences not significant) or the amount of tumor resection. A transient neurological deterioration was observed postoperatively for $43.2 \%$ of patients after GTR compared with $25 \%$ of patients after partial tumor removal (chisquare test: not significant), and $97 \%$ of affected patients had regained their preoperative neurological status after 6 months, with exceptional patients requiring a year or more for recovery.

Overall, permanent surgical morbidity was determined to occur at a rate of $27.5 \%$. This resulted in a higher McCormick grade for $19.6 \%$ of patients. Looking at the different groups of surgeons, permanent morbidity did not decline with growing experience and remained unchanged throughout the overall study period. Significant statistical differences were detected according to the preoperative neurological state, spinal level of the ependymoma, and the presence of tumor hemorrhages. The lowest morbidity was associated with ependymomas of the cervical cord and McCormick Grade I. Surgery on 91 tumors in patients still able to walk resulted in a permanent loss of walking abilities after 15 operations (16.5\%). Although not statistically significant, permanent morbidity increased for patients older than 60 years of age. There was no difference for tumors associated with or without syringomyelia (Table 6).

According to a multiple regression analysis, a low spinal level, advanced age, and a long history were the most influential independent risk factors for permanent surgical morbidity, apart from tumor hemorrhages (Fig. 3) and surgery on a recurrent tumor (Table 7).

The postoperative clinical results for the first 12 months are presented in Table 8. As a general rule, the individu-
TABLE 4. Multivariate analysis of factors predicting a GTR*

\begin{tabular}{lc}
\hline \multicolumn{1}{c}{ Factor } & $\beta$ Value† \\
\hline Low preop McCormick grade & 0.3417 \\
\hline First surgery & 0.3014 \\
\hline No arachnoid scarring & 0.1286 \\
\hline Short history & 0.1093 \\
\hline Experienced surgeon & 0.1084 \\
\hline
\end{tabular}

* Multivariate regression: $r=0.36, p=0.04$.

$\dagger$ Predictive power of an individual factor.

al scores declined postoperatively and improved toward the end of the 1st postoperative year. Overall, the preoperative McCormick grade remained the same for $69.1 \%$ of patients, while $6.2 \%$ showed an improvement. Due to the presence of more severe neurological deficits in patients with thoracic ependymomas, their neurological scores after 1 year remained worse compared with patients with cervical ependymomas. Whereas the postoperative courses for sensory functions, dysesthesias, and pain were quite similar, the differences between both tumor locations for motor function, gait, and bladder control had increased at that time point in favor of cervical ependymomas.

\section{Long-Term Outcome}

Mean follow-up was $77 \pm 91$ months. The overall recurrence rate for benign ependymomas after 10 years was $7.4 \%$, with all recurrences occurring within the first 2 years after surgery. The recurrence rate correlated significantly with the amount of tumor resection (4.2\% after complete vs $18.5 \%$ after incomplete resections within 20 years; log-rank test: $\mathrm{p}=0.03$ ) (Fig. 4).

Seven patients died during follow-up. Two deaths were related to surgery within 4 and 6 weeks, respectively, while 1 patient, aged 64 years, died of complications related to his postoperative paraplegia 1 year later. One patient died at 48 years of age from cranial tumors associated with NF2 23 years after her spinal operation, and 3 patients died from unrelated causes 3,6 , and 26 years later at ages 51,76 , and 82 years, respectively. The corresponding survival rate for 20 years was $92 \%$ according to KaplanMeier analysis.

Apart from tumor recurrences, the quality of life after surgery for an intramedullary ependymoma may be com-

TABLE 5. Postoperative or short-term complications

\begin{tabular}{lc}
\hline Type of Complication & No. of Patients \\
\hline CSF fistula & 4 \\
\hline Infection & 5 \\
\hline Hemorrhage & 2 \\
\hline Lamina dislocation & 1 \\
\hline Spinal Instability & 1 \\
\hline Urinary tract infection & 3 \\
\hline Acute psychosis & 1 \\
\hline Total & $17(16.7 \%)$ \\
\hline
\end{tabular}


TABLE 6. Permanent surgical morbidity

\begin{tabular}{|c|c|c|}
\hline Variable & Rate (\%) & $\mathrm{p}$ Value \\
\hline \multicolumn{3}{|l|}{ Extent of resection } \\
\hline GTR & 27.2 & \multirow[t]{4}{*}{ NS } \\
\hline Subtotal & 50.0 & \\
\hline Partial & 16.7 & \\
\hline Biopsy & - & \\
\hline \multicolumn{3}{|l|}{ Syringomyelia } \\
\hline Present & 28.6 & \multirow[t]{2}{*}{ NS } \\
\hline Absent & 27.8 & \\
\hline \multicolumn{3}{|l|}{ Tumor hemorrhage } \\
\hline Present & 44.0 & \multirow[t]{2}{*}{0.02} \\
\hline Absent & 20.0 & \\
\hline \multicolumn{3}{|l|}{ Walking } \\
\hline w/o aid & 20.6 & \multirow[t]{3}{*}{0.02} \\
\hline w/ aid & 45.5 & \\
\hline Not walking & 36.4 & \\
\hline \multicolumn{3}{|l|}{ McCormick grades } \\
\hline I & 21.7 & \multirow[t]{3}{*}{0.02} \\
\hline ॥ & 47.62 & \\
\hline III + IV & 30.0 & \\
\hline \multicolumn{3}{|l|}{ Location } \\
\hline Cervical & 14.9 & \multirow[t]{2}{*}{0.01} \\
\hline Thoracic + conus & 37.3 & \\
\hline \multicolumn{3}{|l|}{ Age (yrs) } \\
\hline$\leq 60$ & 24.4 & \multirow[t]{2}{*}{ NS } \\
\hline$>60$ & 43.8 & \\
\hline \multicolumn{3}{|c|}{ Period in overall series } \\
\hline A & 32.0 & \multirow[t]{4}{*}{ NS } \\
\hline $\mathrm{B}$ & 20.5 & \\
\hline C & 32.4 & \\
\hline All & 27.5 & \\
\hline
\end{tabular}

NS = not significant.

promised by a neuropathic pain syndrome or a postsurgical myelopathy.

A neuropathic pain syndrome was observed after $37.0 \%$ of operations and always started a few weeks or months after surgery. No significant differences for any subgroups could be detected. The rate of patients affected by neuropathic pain syndromes remained stable throughout the overall study period. In a multivariate analysis, preoperative neuropathic pain, permanent surgical morbidity, a low preoperative McCormick score, advanced age, and no tumor hemorrhage were the strongest predictors for this syndrome, while GTR, female sex, and postoperative tethering of the cord to the dura had less predictive power (Table 9).

Four percent of operations were followed by clinical signs of a myelopathy unrelated to a recurrent tumor growth. This phenomenon was seen exclusively in patients with postoperative fixation of the spinal cord to the dura and affected $10 \%$ of those with radiological evidence of postoperative cord tethering (Fig. 5).

\section{Discussion}

This study describes results for 100 patients with intramedullary ependymomas treated at Nordstadt Hospital Hannover, Germany, from 1980 to 2003 and the Christliche Krankenhaus Quakenbrück, Germany, from 2004 to 2014. Ependymomas accounted for $40 \%$ of all intramedullary tumors operated on in that 34-year period. They are the most common intramedullary tumor in adults; only 3 children presented with this tumor type in this series.

The introduction of MRI has revolutionized the diagnosis of intramedullary tumors. The neuroradiological features of ependymomas are quite variable. ${ }^{25}$ Although most ependymomas are midline tumors (Figs. 1,3, and 5), some may display an eccentric growth pattern, even with an extramedullary component (Fig. 2). They may appear solid and well demarcated with homogenous contrast enhancement (Fig. 5) while others display a patchy contrast uptake (Fig. 2) or appear cystic (Fig. 3). In this series, $24.5 \%$ of ependymomas displayed evidence of tumor hemorrhages, either as hemosiderin caps on either tumor pole (Fig. 5) or as intramedullary hemorrhages into an accompanying syrinx (Fig. 3) or the tumor itself. The only sudden neurological deterioration in this series was observed with such an intratumoral hemorrhage in 1 patient. An associated syrinx was detected in $58 \%$ of patients.

The rarity of intramedullary tumors, in general, and their slow-growing nature may explain the rather long average preoperative history of almost 3 years before presentation. Due to advances in MRI, patients present with less neurological deficits and lower McCormick scores nowadays compared with the 1980s (Table 3). Prior to 1990 (Period A), the majority of patients presented with McCormick Grades II and III, with 24\% of them no longer able to walk by the time of diagnosis. Since 1991, the great majority of patients are diagnosed in Grade I, with only $4 \%-6 \%$ of patients wheelchair dependent by the time of presentation.

Another interesting aspect is the trend for more severe neurological deficits associated with ependymomas of the thoracic cord and conus compared with cervical lesions (Tables 2 and 8). By comparison, cervical tumors tended to produce more sensory deficits and dysesthesias. The larger size of the cervical cord compared with the thoracic cord may explain these effects, as tumors had to reach larger volumes in the cervical cord to produce severe neurological deficits.

\section{Resection Results}

Every operation on an intramedullary tumor should attempt a GTR. ${ }^{11}$ In this series, $86.3 \%$ of ependymomas underwent GTR, , , ,5-7,10,16,19,20,28-30,33 with a steady increase of this rate throughout the overall study period. The major reasons for the steadily increasing GTR rates appear to be the improvements in preoperative MRI as well as the intraoperative ultrasound visualization, the introduction of small ultrasonic aspirators, and increasing experience of neurosurgeons. The influence of experience on GTR rates is evident by comparing results for the 3 different groups of surgeons in this study.

The multivariate analysis disclosed a number of in- 




FIG. 3. Case of a 65-year-old man with an ependymoma at the T8-11 level, with a 15-month history of local pain followed by slight gait ataxia and sphincter problems. A-E: The cystic tumor with evidence of hematomyelia due to a hemorrhage into the accompanying syrinx is shown in sagittal (A) and axial (B) T2-weighted MR images. The hemorrhage had caused no sudden aggravations of symptoms. Comparison of T1-weighted images before $(C)$ and after gadolinium application ( $D$ and $E$ ) reveals patchy contrast uptake of the tumor. Postoperatively, the patient's neurological state worsened for 5 months, when he had reached his preoperative state again. He did not develop a neuropathic pain syndrome. The postoperative T1-weighted MR image with contrast (F) 2 years later showing no tumor remnant or recurrence after GTR, with slight adhesions between cord and dura on the axial T2-weighted image (G). No pain syndrome or myelopathy have developed.

dependent factors predicting a GTR. A low McCormick grade $^{19}$ and operating on a de novo rather than a recurrent ependymoma were the strongest predictors for a GTR. Other independent factors favoring a GTR were absence of arachnoid adhesions between cord and dura, a short clinical history, and an experienced surgeon (Table 4). In other words, GTRs were more likely in patients with a less compromised spinal cord operated on by an experienced surgeon.

A few comments on the surgical strategy may be warranted here (Figs. 1 and 2). Obviously, monitoring of somatosensory-evoked potentials may aid the surgeon to preserve sensory functions during myelotomy and further dissection and is highly recommended. It will not only help to preserve sensory functions but also indicate how an individual tumor can and should be handled throughout the remaining operation. It was the general policy of the 2 institutions involved in the series to open the spinal cord over the entire tumor before starting any further dissection or debulking. Pial retention sutures were applied in most instances to keep the spinal cord open so that further dissection could concentrate on tumor dissection and removal without having to open the cord each time for every surgical step. All tumors were debulked first. Quite often, the tumor became better demarcated from normal cord tissue once a considerable amount was removed and the tumor partially devascularized. When the anterior surface of the tumor was reached, monitoring was switched to motorevoked potentials. The characteristic feature of ependymomas is their main vascularization from small branches of

TABLE 7. Multivariate analysis of risk factors for permanent surgical morbidity*

\begin{tabular}{lc}
\hline \multicolumn{1}{c}{ Factor } & $\beta$ Value† \\
\hline Thoracic level & 0.2488 \\
\hline Advanced age & 0.2371 \\
\hline Long history & 0.2306 \\
\hline Tumor hemorrhage & 0.2063 \\
\hline Secondary surgery & 0.1505 \\
\hline
\end{tabular}

\footnotetext{
* Multivariate regression: $r=0.51, p=0.0002$.
}

$\dagger$ Predictive power of an individual factor. 
TABLE 8. Preoperative and postoperative neurological scores for patients with intramedullary ependymomas*

\begin{tabular}{|c|c|c|c|}
\hline \multirow[b]{2}{*}{ Symptom } & \multicolumn{3}{|c|}{ Location } \\
\hline & Cervical & Thoracic + Conus & All \\
\hline \multicolumn{4}{|l|}{ Hypesthesia } \\
\hline Preop & $3.5 \pm 0.8$ & $3.4 \pm 1.0$ & $3.4 \pm 0.9$ \\
\hline Postop & $2.6 \pm 0.6$ & $2.1 \pm 1.0$ & $2.3 \pm 0.9$ \\
\hline $3 \mathrm{mos}$ & $2.7 \pm 0.6$ & $2.2 \pm 1.1$ & $2.4 \pm 0.9$ \\
\hline $6 \mathrm{mos}$ & $2.8 \pm 0.6$ & $2.3 \pm 1.1$ & $2.5 \pm 0.9$ \\
\hline 1 Year & $2.8 \pm 0.6$ & $2.3 \pm 1.1$ & $2.5 \pm 0.9$ \\
\hline \multicolumn{4}{|l|}{ Dysesthesia } \\
\hline Preop & $3.9 \pm 0.9$ & $4.1 \pm 0.9$ & $4.0 \pm 0.9$ \\
\hline Postop & $3.8 \pm 0.8$ & $4.1 \pm 0.9$ & $4.0 \pm 0.8$ \\
\hline $3 \mathrm{mos}$ & $3.6 \pm 0.7$ & $4.0 \pm 0.9$ & $3.8 \pm 0.9$ \\
\hline $6 \mathrm{mos}$ & $3.6 \pm 0.9$ & $4.0 \pm 1.0$ & $3.8 \pm 1.0$ \\
\hline $1 \mathrm{yr}$ & $3.5 \pm 0.9$ & $3.9 \pm 0.9$ & $3.7 \pm 0.9$ \\
\hline \multicolumn{4}{|l|}{ Pain } \\
\hline Preop & $4.4 \pm 0.8$ & $3.9 \pm 0.9$ & $4.1 \pm 0.9$ \\
\hline Postop & $4.2 \pm 0.7$ & $3.9 \pm 0.9$ & $4.0 \pm 0.8$ \\
\hline $3 \mathrm{mos}$ & $4.6 \pm 0.6$ & $4.2 \pm 0.9$ & $4.4 \pm 0.8$ \\
\hline $6 \mathrm{mos}$ & $4.7 \pm 0.5$ & $4.3 \pm 1.0$ & $4.5 \pm 0.8$ \\
\hline $1 \mathrm{yr}$ & $4.7 \pm 0.5$ & $4.3 \pm 1.0$ & $4.5 \pm 0.8$ \\
\hline \multicolumn{4}{|l|}{ Motor weakness } \\
\hline Preop & $4.3 \pm 0.8$ & $3.9 \pm 1.1$ & $4.1 \pm 1.0$ \\
\hline Postop & $3.7 \pm 1.0$ & $2.7 \pm 1.6$ & $3.1 \pm 1.4$ \\
\hline $3 \mathrm{mos}$ & $3.9 \pm 0.8$ & $3.0 \pm 1.6$ & $3.4 \pm 1.3$ \\
\hline $6 \mathrm{mos}$ & $4.1 \pm 0.8$ & $3.2 \pm 1.6$ & $3.6 \pm 1.4$ \\
\hline $1 \mathrm{yr}$ & $4.2 \pm 0.8$ & $3.2 \pm 1.6$ & $3.6 \pm 1.4$ \\
\hline \multicolumn{4}{|l|}{ Gait ataxia } \\
\hline Preop & $4.4 \pm 0.6$ & $3.6 \pm 1.1$ & $3.9 \pm 1.0$ \\
\hline Postop & $3.3 \pm 1.0$ & $2.2 \pm 1.5$ & $2.7 \pm 1.4$ \\
\hline $3 \mathrm{mos}$ & $3.8 \pm 1.0$ & $2.6 \pm 1.7$ & $3.1 \pm 1.5$ \\
\hline $6 \mathrm{mos}$ & $3.9 \pm 0.9$ & $2.9 \pm 1.7$ & $3.3 \pm 1.5$ \\
\hline $1 \mathrm{yr}$ & $4.0 \pm 0.8$ & $2.9 \pm 1.7$ & $3.3 \pm 1.5$ \\
\hline \multicolumn{4}{|c|}{ Bladder dysfunction } \\
\hline Preop & $4.8 \pm 0.4$ & $4.5 \pm 1.0$ & $4.6 \pm 0.8$ \\
\hline Postop & $4.3 \pm 1.2$ & $2.9 \pm 1.9$ & $3.6 \pm 1.7$ \\
\hline $3 \mathrm{mos}$ & $4.5 \pm 0.8$ & $3.4 \pm 1.8$ & $3.9 \pm 1.5$ \\
\hline $6 \mathrm{mos}$ & $4.6 \pm 0.7$ & $3.6 \pm 1.8$ & $4.0 \pm 1.5$ \\
\hline $1 \mathrm{yr}$ & $4.7 \pm 0.6$ & $3.6 \pm 1.8$ & $4.1 \pm 1.5$ \\
\hline
\end{tabular}

* Values are mean \pm standard deviation

the anterior spinal cord artery. Identification, coagulation, and transsection of these feeders were the last steps of tumor removal and required utmost care. Anesthetists were instructed to keep the mean arterial pressure high enough during this part of the surgery in particular. Excessive tension must not be applied to these feeders to avoid undue tension on the anterior spinal cord artery. Feeders were coagulated and cut close to the tumor rather than close to the artery. Finally, bipolar coagulation should be used as little as possible inside the spinal cord, applying repeated irrigation for hemostasis instead.

\section{Surgical Morbidity}

Complications such as postoperative hemorrhages, problems related to wound healing, or infections were observed at a rate of $16.7 \%$ and treatable without long-term

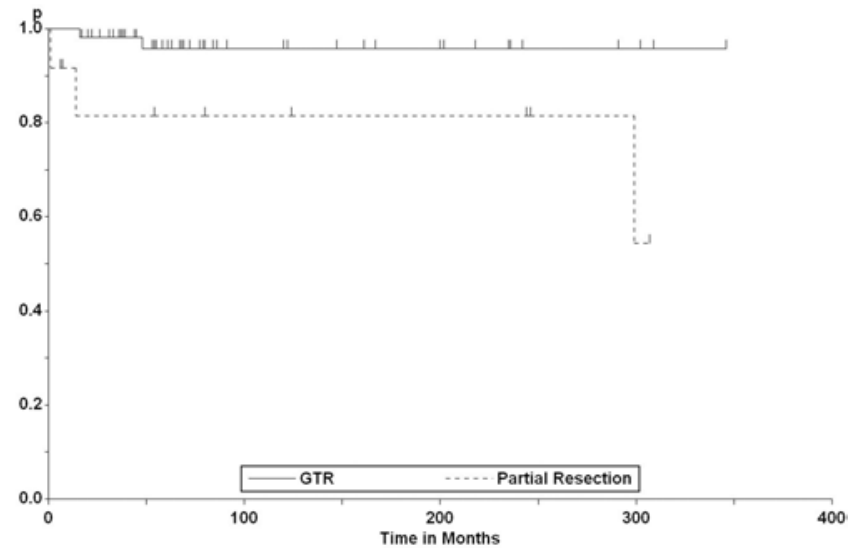

FIG. 4. Kaplan-Meier analysis of tumor recurrence rates for intramedullary ependymomas related to the amount of tumor resection (log-rank test: $p=0.03$ ).

sequelae provided they were managed appropriately and in time.

No anesthesiological complications occurred among patients operated on in the semisitting position. Risks for air embolism can be minimized by careful dissection of neck muscles and covering the lateral epidural spaces with moist cottonoids. This is particularly helpful during dura closure, as epidural veins, which are no longer under compression from the neoplasm, may start bleeding due to manipulations of the dura.

Almost all patients experienced a worse neurological status as soon as they woke up from anesthesia. This immediate postoperative worsening involved sensory functions for almost all patients. ${ }^{6,19,21,29}$ Postoperative sensory deficits are an inevitable consequence of the myelotomy required to reach an intramedullary tumor. ${ }^{16,21}$ The length of the myelotomy was found to correlate with postoperative sensory dysfunctions in several studies..$^{4,5,19,30}$ The only tumors which could be removed without inflicting such sensory disturbances were those that had reached the pia mater or grown out of the cord in exophytic fashion. In such cases, the tumor could be entered directly without requiring a myelotomy (Fig. 2). During the postoperative course, some improvement of sensory symptoms did take place. However, in the great majority, this recovery was incomplete and ended within 6 months after surgery (Table 8). ${ }^{6,29}$ Apart from impaired sensations for light touch, temperature, and pain, which may render patients vulnerable to unnoticed injuries, specific problems related to impaired joint position sense are common.

For this study, surgical morbidity was defined as a postoperative worsening of motor power, gait, or sphincter functions irrespective of postoperative changes for sensory functions or pain. In this series, $67.6 \%$ of all patients experienced such surgical morbidity to some degree. This deterioration was transient for $40.1 \%$ of patients and permanent in $27.5 \%$. Postoperative improvements were sometimes observed, but keeping the preoperative functional state was the realistic prognosis for the great majority of patients $^{6}$ (Table 8 ). Indeed, the majority of patients keep their preoperative functional state, and only few patients improve on it. This remains the strongest argument to rec- 
TABLE 9. Multivariate analysis of risk factors for a postoperative neuropathic pain syndrome*

\begin{tabular}{lc}
\hline \multicolumn{1}{c}{ Factor } & $\beta$ Value \\
\hline Preoperative neuropathic pain & 0.3144 \\
\hline Permanent morbidity & 0.2828 \\
\hline Low preop McCormick grade & 0.2438 \\
\hline Increasing age & 0.2110 \\
\hline No tumor hemorrhage & 0.2093 \\
\hline GTR & 0.1536 \\
\hline Female sex & 0.1449 \\
\hline Postoperative cord tethering & 0.1387 \\
\hline
\end{tabular}

* Multivariate regression: $r=0.48, p=0.02$

$\dagger$ Predictive power of an individual factor. ommend surgery early. A watch-and-wait policy cannot be supported. . $3,3,5,16,18,19,27,32^{2}$

\section{Transient Morbidity}

Further analysis showed a trend for higher rates of postoperative transient morbidity with increasing age., ${ }^{7,31}$ Elderly patients demonstrated more difficulties to overcome deficits of joint position sense in particular. Transient postoperative neurological deteriorations were more common after GTRs than partial resections and after operations by experienced surgeons of Group $\mathrm{C}$, who were more likely to remove a tumor completely. The time for recovery was quite variable and required intensive, professional rehabilitation and active training by the patient. It took up to 6 months for the majority, but continued for a year or even longer in some patients. ${ }^{2,6,16}$
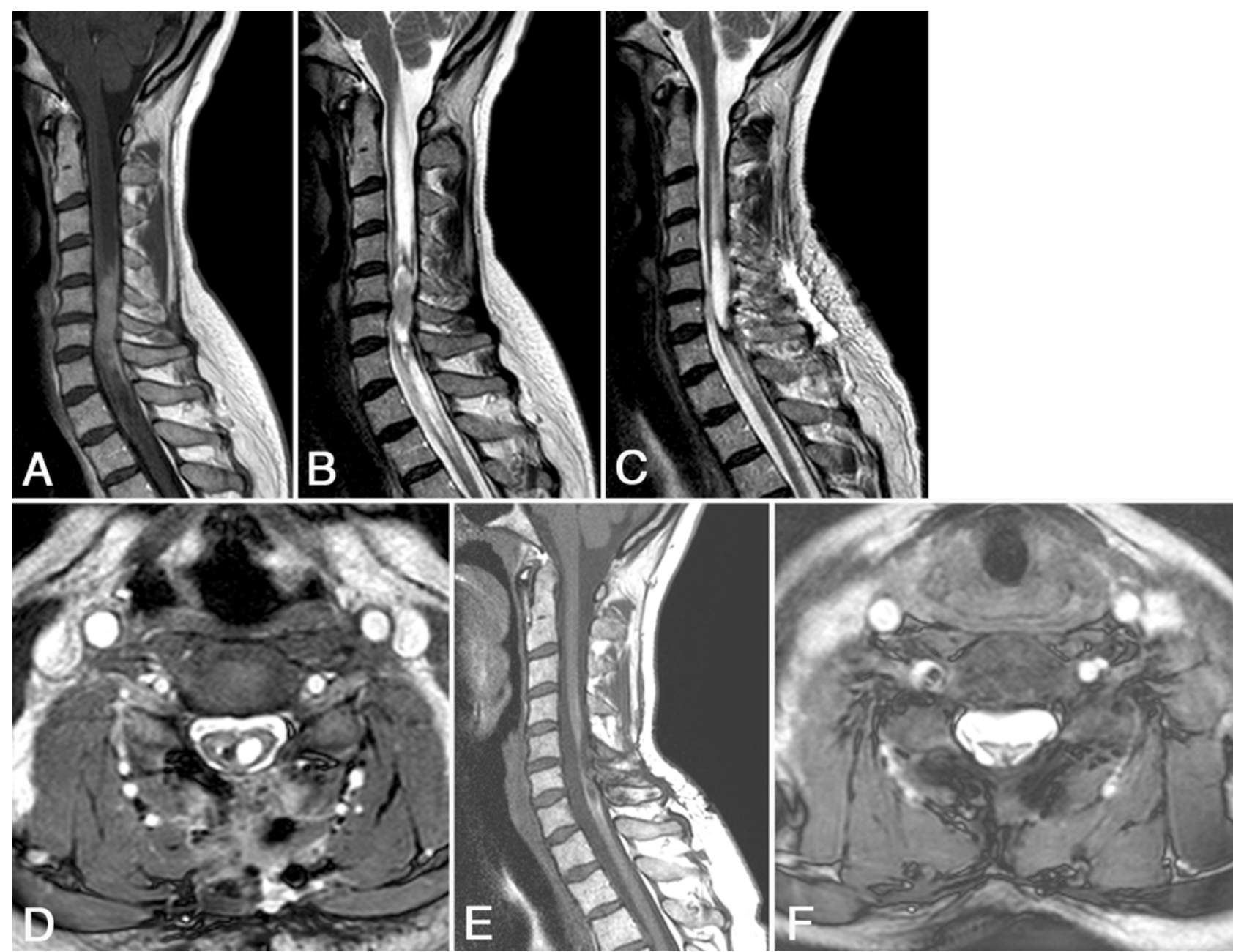

FIG. 5. Case of a 54-year-old woman with an ependymoma at the C5-7 level, with a 2-year history of dysesthesias, pain, and a progressive tetraparesis. A: Sagittal T1-weighted MR image with contrast showing a solid tumor with contrast enhancement and irregular demarcation posteriorly and at both tumor poles. B: T2-weighted MR image demonstrating a more clearly defined tumor mass with hemosiderin caps on both tumor poles related to small hemorrhages. C: Postoperative sagittal T2-weighted MR image showing the complete resection with preservation of the gliosis containing the hemosiderin. D: Axial T2-weighted MR image showing the remaining cord tissue after resection and some hemosiderin close to the midline. Postoperatively, the patient regained her neurological functions after 5 months but developed a neuropathic pain syndrome and neurological signs of a progressing myelopathy 15 months after surgery. $\mathbf{E}$ and $\mathrm{F}$ : The corresponding T1-weighted MR image with contrast (E) and the axial T2-weighted MR image (F) 15 months after surgery demonstrating no tumor recurrence but profound cord atrophy and adhesions between cord and dura. 


\section{Permanent Morbidity}

The rather high rate of permanent surgical morbidity for intramedullary ependymomas is disturbing. This rate of $27.5 \%$ is by far the highest compared with all other intramedullary tumor types. ${ }^{11}$ Publications reporting permanent morbidity rates for intramedullary tumors are few, not to mention rates for separate entities. For all histological types combined, rates between $13.9 \%$ and $34.6 \%$ have been published in the literature., ${ }^{1,2,21,22,27}$ Fischer and Brotchi ${ }^{6}$ documented a postoperative increase in the McCormick grade 1 year after surgery in 19\% of patients for all histological entities combined. Three previous publications on large series of ependymomas reported rates of $4.5 \%,{ }^{19} 13.9 \%,{ }^{2}$ and $35.8 \%{ }^{16}$ for patients with a worse postoperative McCormick grade after surgery. Thus, the rate of $19.6 \%$ of patients losing a McCormick grade with surgery in this study is in the reported range. The rate of $4.5 \%$ reported by $\mathrm{Li}$ et al. ${ }^{19}$ with only $13.3 \%$ of patients experiencing new postoperative sensory deficits, appears exceptional but may, in part, be explained by inclusion of myxopapillary ependymomas as intramedullary tumors in their study.

Several factors were found to influence permanent morbidity independently (Table 7); surprisingly, the preoperative neurological state was not among them. A low spinal level of the tumor, $, 311,17,25$ advanced age, a long clinical history, and tumor hemorrhages had the strongest predictive power, apart from operating on a recurrent tumor. The higher permanent morbidity for thoracic ependymomas may be a consequence of their vascularization pattern mentioned above and the more vulnerable vascular supply of the thoracic cord compared with that of the cervical cord. The importance of maintaining a sufficient arterial blood pressure during tumor removal cannot be overemphasized. Furthermore, thoracic ependymomas presented with more severe neurological deficits resulting more often in a McCormick Grade II or III before surgery. Fischer and Brotchi ${ }^{6}$ and Stein and McCormick ${ }^{29}$ mentioned the conus area as a particularly dangerous region; otherwise, this increased morbidity of thoracic ependymomas has not been described previously. The increased morbidity for elderly patients may be explained by a loss of spinal cord plasticity and mental factors. Patients of advanced age often have larger difficulties to overcome deficits of joint position sense in particular. Finally, tumor hemorrhages and surgery on recurrent tumors render dissection more difficult due to formation of gliotic tissue in areas of former bleeding or surgery.

Does limiting tumor removal to a subtotal resection reduce permanent morbidity ${ }^{19}$ ? The data from this study do not support this assumption (Table 6 ), ${ }^{16,22}$ bearing in mind, however, that the number of patients undergoing subtotal or partial removals was low. The factors affecting permanent morbidity for intramedullary ependymomas are not different from those for other histological types..1 The risks, however, appear to be higher in general. The best explanation for this appears to be the vascularization pattern of ependymomas. Applying too much tension on the anterior spinal cord artery and damaging perforating arteries during dissection are more likely to occur in this tumor entity compared with any other. This concerns thoracic tu- mors in particular. Paying attention to these factors, securing a sufficiently high blood pressure throughout dissection, and monitoring motor-evoked potentials reduce these risks considerably. Furthermore, thoracic ependymomas, in particular, should be brought to surgery before significant deficits have developed.

\section{Long-Term Outcome}

This study, as others before, has demonstrated that recurrence rates depend on the amount of tumor resection. ${ }^{6,10,17}$ A GTR of an ependymoma was a curative operation for $95.8 \%$ of patients in this study (Fig. 4). As one would expect for a benign tumor entity, mortality figures are low, with $92 \%$ surviving at least 20 years. Among 7 deaths in this series, only 3 were related to the ependymoma that was operated on, while 4 patients died of other tumors associated with NF2 or unrelated causes.

However, the clinical outcome does not depend on tumor recurrences and immediate postoperative morbidities alone. Even patients who underwent a GTR and made a gratifying neurological recovery may suffer from significant neuropathic pain syndromes or develop a severe myelopathy at a later stage.

In this study, $4 \%$ of patients developed a postsurgical myelopathy, which usually started a few months after surgery. This delayed complication was observed exclusively in patients with MRI evidence of postoperative tethering of the spinal cord to the dura ${ }^{8}$ (Fig. 5). During the overall study period, the incidence of such tetherings could be reduced significantly with pial sutures, whereas duraplasties had no protective effect in this respect. Goto et al. ${ }^{8}$ likewise limited postsurgical tethering by combining pial suturing with a duraplasty. Therefore, pial sutures are recommended after GTR or a subtotal removal; they never led to syrinx formation in this series. No attempt was undertaken to untether a spinal cord in patients affected by a myelopathy. Such an attempt on an often very atrophic cord carries considerable risks. Furthermore, judging from experiences on patients undergoing a second operation for arachnolysis and untethering for syringomyelia, the probability of postoperative retethering and additional permanent morbidity is high. ${ }^{12}$

Neuropathic pain syndromes are the other late postoperative complication, which may appear a few weeks to months after surgery. $6,19,24,26,28,29$ Thirty-seven percent of patients were affected in this study. Similar to the permanent surgical morbidity rate for ependymomas, this figure for neuropathic pain syndromes was the highest among all tumor types. ${ }^{11}$ Fischer and Brotchi ${ }^{6}$ observed long-term pain syndromes in $37.4 \%$ of patients following surgery of their intramedullary tumors. Other studies provided rates between $19 \%{ }^{24}$ and $60 \% .{ }^{26}$ In this study, only permanent types of pain requiring medication were classified as a neuropathic pain syndrome. Most patients decribed this pain as a burning type. The wide reported range in the literature may be explained by the lack of a precise definition of this syndrome. The pathophysiological mechanism is not well established either. The higher rates of neuropathic pain after GTR and in patients with permanent surgical morbidity as determined in the multivariate analysis suggest that surgical manipulation may play a role. Li et 
al. ${ }^{19}$ found neuropathic pain syndromes to be particularly common in tumors extending over more than $10 \mathrm{~cm}$, thus pointing in a similar direction. The strongest independent factor predicting this syndrome in this study was the preoperative presence of neuropathic pain. In other words, the tumor itself may also produce this problem. Postoperative cord tethering, on the other hand, had the least influence of all risk factors listed in Table 9. Therefore, this syndrome may simply be the result of a severely damaged spinal cord due to tumor expansion and surgery. The analysis does not provide any clues as to how this often debilitating problem might be avoided. Fortunately, treatment with gabapentin or pentagabalin-drugs unavailable early during the overall study period-and anticonvulsants has been moderately successful in recent years.

\section{Conclusions}

Intramedullary ependymomas are tumors to be treated surgically. A GTR indicates cure for the overwhelming majority of patients. GTR rates above $90 \%$ represent the state of the art but require considerable experience. Rates for permanent surgical morbidity and neuropathic pain syndromes, however, are the highest among all intramedullary tumor types and affect a significant proportion of patients. This study found considerably better treatment results for cervical tumors compared with thoracic levels, which were also associated with more severe preoperative neurological deficits. Morbidity rates can be kept to a minimum by performing surgery early before severe neurological deficits have developed.

\section{Acknowledgments}

The author wishes to express his gratitude to Prof. Madjid Samii, who supervised the author's neurosurgical training, taught the author how to operate on these challenging lesions, and enabled this study as well as the establishment of the spinal cord database by attracting large numbers of patients with spinal cord pathologies to his neurosurgical clinic in Hannover. The author wishes to acknowledge the leadership of Drs. Madjid Samii (1977-2002) and Michael Gaab (2003-2013) in their tenures as Chairman of the Neurosurgical Department in Hannover (Nordstadt Hospital).

\section{References}

1. Adam Y, Benezech J, Blanquet A, Fuentes JM, Bousigue JY, Debono B, et al: [Intramedullary tumors. Results of a national investigation in private neurosurgery.] Neurochirurgie 56:344-349, 2010 (Fr)

2. Aghakhani N, David P, Parker F, Lacroix C, Benoudiba F, Tadie M: Intramedullary spinal ependymomas: analysis of a consecutive series of 82 adult cases with particular attention to patients with no preoperative neurological deficit. Neurosurgery 62:1279-1286, 2008

3. Boström A, von Lehe M, Hartmann W, Pietsch T, Feuss M, Boström JP, et al: Surgery for spinal cord ependymomas: outcome and prognostic factors. Neurosurgery 68:302-309, 2011

4. Ebner FH, Roser F, Falk M, Hermann S, Honegger J, Tatagiba M: Management of intramedullary spinal cord lesions: interdependence of the longitudinal extension of the lesion and the functional outcome. Eur Spine J 19:665-669, 2010

5. Eroes CA, Zausinger S, Kreth FW, Goldbrunner R, Tonn JC:
Intramedullary low grade astrocytoma and ependymoma. Surgical results and predicting factors for clinical outcome. Acta Neurochir (Wien) 152:611-618, 2010

6. Fischer G, Brotchi J: Intramedullary Spinal Cord Tumors. Stuttgart: Thieme, 1996

7. Garcés-Ambrossi GL, McGirt MJ, Mehta VA, Sciubba DM, Witham TF, Bydon A, et al: Factors associated with progression-free survival and long-term neurological outcome after resection of intramedullary spinal cord tumors: analysis of 101 consecutive cases. J Neurosurg Spine 11:591-599, 2009

8. Goto T, Ohata K, Takami T, Nishikawa M, Nishio A, Morino $\mathrm{M}$, et al: Prevention of postoperative posterior tethering of spinal cord after resection of ependymoma. J Neurosurg 99 (2 Suppl):181-187, 2003

9. Kaplan EL, Meier P: Nonparametric estimation from incomplete observations. J Am Stat Assoc 53:457-481, 1958

10. Karikari IO, Nimjee SM, Hodges TR, Cutrell E, Hughes BD, Powers CJ, et al: Impact of tumor histology on resectability and neurological outcome in primary intramedullary spinal cord tumors: a single-center experience with 102 patients. Neurosurgery 68:188-197, 2011

11. Klekamp J: Treatment of intramedullary tumors: analysis of surgical morbidity and long-term results. J Neurosurg Spine 19:12-26, 2013

12. Klekamp J: Treatment of syringomyelia related to nontraumatic arachnoid pathologies of the spinal canal. Neurosurgery 72:376-389, 2013

13. Klekamp J, Samii M: Introduction of a score system for the clinical evaluation of patients with spinal processes. Acta Neurochir (Wien) 123:221-223, 1993

14. Klekamp J, Samii M: Surgery of Spinal Tumors. Berlin: Springer, 2007

15. Klekamp J, Samii M: Syringomyelia - Diagnosis and Treatment. Berlin: Springer, 2001

16. Kucia EJ, Bambakidis NC, Chang SW, Spetzler RF: Surgical technique and outcomes in the treatment of spinal cord ependymomas, part 1: intramedullary ependymomas. Neurosurgery 68 (1 Suppl Operative):57-63, 2011

17. Lee SH, Chung CK, Kim CH, Yoon SH, Hyun SJ, Kim KJ, et al: Long-term outcomes of surgical resection with or without adjuvant radiation therapy for treatment of spinal ependymoma: a retrospective multicenter study by the Korea Spinal Oncology Research Group. Neuro Oncol 15:921-929, 2013

18. Lee SM, Cho YE, Kwon YM: Neurological outcome after surgical treatment of intramedullary spinal cord tumors. Korean J Spine 11:121-126, 2014

19. Li TY, Chu JS, Xu YL, Yang J, Wang J, Huang YH, et al: Surgical strategies and outcomes of spinal ependymomas of different lengths: analysis of 210 patients: clinical article. J Neurosurg Spine 21:249-259, 2014

20. Malis LI: Intramedullary spinal cord tumors. Clin Neurosurg 25:512-539, 1978

21. Manzano G, Green BA, Vanni S, Levi AD: Contemporary management of adult intramedullary spinal tumors-pathology and neurological outcomes related to surgical resection. Spinal Cord 46:540-546, 2008

22. Matsuyama Y, Sakai Y, Katayama Y, Imagama S, Ito Z, Wakao N, et al: Surgical results of intramedullary spinal cord tumor with spinal cord monitoring to guide extent of resection. J Neurosurg Spine 10:404-413, 2009

23. McCormick PC, Torres R, Post KD, Stein BM: Intramedullary ependymoma of the spinal cord. J Neurosurg 72:523532,1990

24. McGirt MJ, Chaichana KL, Atiba A, Attenello F, Yao KC, Jallo GI: Resection of intramedullary spinal cord tumors in children: assessment of long-term motor and sensory deficits. J Neurosurg Pediatr 1:63-67, 2008

25. Miyazawa N, Hida K, Iwasaki Y, Koyanagi I, Abe H: MRI at $1.5 \mathrm{~T}$ of intramedullary ependymoma and classification of 
pattern of contrast enhancement. Neuroradiology 42:828832,2000

26. Nakamura M, Tsuji O, Iwanami A, Tsuji T, Ishii K, Toyama Y, et al: Central neuropathic pain after surgical resection in patients with spinal intramedullary tumor. J Orthop Sci 17:352-357, 2012

27. Sandalcioglu IE, Gasser T, Asgari S, Lazorisak A, Engelhorn T, Egelhof T, et al: Functional outcome after surgical treatment of intramedullary spinal cord tumors: experience with 78 patients. Spinal Cord 43:34-41, 2005

28. Stein BM: Surgery of intramedullary spinal cord tumors. Clin Neurosurg 26:529-542, 1979

29. Stein BM, McCormick PC: Intramedullary neoplasms and vascular malformations. Clin Neurosurg 39:361-387, 1992

30. Sun J, Wang Z, Li Z, Liu B: Microsurgical treatment and functional outcomes of multi-segment intramedullary spinal cord tumors. J Clin Neurosci 16:666-671, 2009

31. Wang ZY, Sun JJ, Xie JC, Li ZD, Ma CC, Liu B, et al: Comparative analysis on the diagnosis and treatments of multisegment intramedullary spinal cord tumors between the different age groups. Neurosurg Rev 35:85-93, 2012
32. Woodworth GF, Chaichana KL, McGirt MJ, Sciubba DM, Jallo GI, Gokaslan Z, et al: Predictors of ambulatory function after surgical resection of intramedullary spinal cord tumors. Neurosurgery 61:99-106, 2007

33. Yang S, Yang X, Hong G: Surgical treatment of one hundred seventy-four intramedullary spinal cord tumors. Spine (Phila Pa 1976) 34:2705-2710, 2009

\section{Supplemental Information \\ Companion Paper}

Klekamp J: Spinal ependymomas. Part 2: Ependymomas of the filum terminale. DOI: 10.3171/2015.5.FOCUS15151.

\section{Correspondence}

Jörg Klekamp, Department of Neurosurgery, Christliches Krankenhaus, Danziger Str. 2, Quakenbrück 49610, Germany. email: j.klekamp@ckq-gmbh.de. 